\title{
A Method Impact Assessment Framework for User Experience Evaluations with Children
}

\author{
Gavin Sim \\ University of Central Lancashire \\ Preston, UK. \\ grsim@uclan.ac.uk
}

\author{
Bieke Zaman \\ KU Leuven \\ Leuven, Belgium. \\ bieke.zaman@kuleuven.be
}

\author{
Matthew Horton \\ University of Central Lancashire \\ Preston, UK. \\ mplhorton@uclan.ac.uk
}

\begin{abstract}
Based upon a review of the literature, this paper presents a Method Impact Assessment Framework. Theoretically synthesized, the framework offers five dimensions: (1) the role of the child, (2) the user experience construct, (3) system, (4) epistemological perspective, (5) Practical and Ethical Concerns. Although other dimensions could have been construed, these were judged to be the most pertinent to understanding evaluation methods with children. The framework thus provides a critical lens in which evaluation methods can be assessed by the Children Computer Interaction ( $\mathrm{CCl})$ Community to inform method selection.
\end{abstract}

\section{Child Computer Interaction. Evaluation Methods. User Experience.}

\section{INTRODUCTION}

The field of Human Computer Interaction $(\mathrm{HCl})$ and Children Computer Interaction (CCl) is characterized by numerous emergent evaluation methods. These have arisen as a response to deal with new, non-traditional, research phenomena surrounding the design, and use of, state of the art technologies and as a result of the typical quest towards innovation in $\mathrm{HCl}$ research and practice. In $\mathrm{CCl}$ research, this started with the first attempts to find appropriate methods to involve children as testers in the evaluation of the technology's usability (Hanna et al., 1997). Today, we observe a wider variety of methods with varying degrees of child participation and dealing with various issues, of which user experiences and children's fun in interacting with technologies have probably gained most attention (Read, 2012, Zaman and Abeele, 2010).

Notwithstanding the numerous methods in $\mathrm{CCl}$ research, we argue that a critical reflection on the impact of the method choice has generally received too little attention. It is important though, as the rationale underlying method selection greatly determines how to judge and value the study's outcomes. To some extent, previous research has presented some criteria to assess the appropriateness of usability methods (Hartson et al., 2003, Bell, 2007, Markopoulos and Bekker, 2003). Although these studies focus on aspects such as validity and effectiveness, the arguments in the discussion do not touch upon any of the epistemological fundaments of the research. To our knowledge there is a lack of standard criteria for determining the appropriateness of user experience methods in $\mathrm{CCl}$. Within $\mathrm{HCl}$ there have been a number of frameworks developed for understanding user experience (Forlizzi and Battarbee, 2004, Schulze and Kromker, 2010) and these differ significantly in the theoretical foci. The difference lies in the interpretation of user experience from a theoretical perspective and the probable explanation for these differences is the fact that a shared definition and concrete operationalization of the construct of user experience is lacking (Law et al., 2009). According to the International Organization for Standardization (ISO) user experience is defined as 'a person's perceptions and responses that result from the use or anticipated use of a product or service' (ISO, 2010). This definition does not address the broad range of concepts associated within user experience and the complex interaction between users and a product. In Hassenzahl et al. (2010) framework they examined the needs of the user and usage models of a product. This model was refined by Pucillo and Cascini (2014) whom added affordances within the product dimension of the framework. These frameworks relating to user experience within $\mathrm{HCl}$ are predominately used to aid the design rather than to facilitate the evaluation of a system or products.

There is a desire to evaluate the entire user experience of an interactive product (Schulze and Kromker, 2010), yet the choice of method and variables to investigate relies on the judgment of the researcher. We therefore argue that we need a 
framework to be able to assess the impact of method choice in $\mathrm{CCl}$ research, as it will provide the research community with a theoretical lens to look at method choices and a concrete lingua franca to talk about it and judge its appropriateness. In this paper, a framework for method impact assessment within $\mathrm{CCl}$ is synthesized based upon a theoretical underpinning.

\section{RELATED WORK}

Based on a thorough literature study, analysis of existing frameworks, we will present four pillars that shape the method choice in $\mathrm{CCl}$ user experience research, namely the (1) epistemological grounds, (2) the definition of the construct of user experience, (3) the child-orientedness, and (4) the system. These four pillars are embedded within the practical and ethical requirements of conducting user studies with children to create five dimensions. There is a complex relationship between these dimensions. The epistemological perspective and practical and ethical considerations can have a direct impact on the other dimensions and thus should not be viewed as separate entities. For example, psychological research on investigative interviewing has come from the experimental paradigm, a positivist perspective, where children are construed as passive participants (Westcott and Littleton, 2005). This would impact on the role of the child as the focus would be on what information can be got from the child, rather than the interpretivist view which may seek to understand the gaps between reality, experiences and expression within the life of the child. The paradigm would therefore influence the constructs being captured, the choice of method, the interaction with the child and actions within the software.

\subsection{Epistemological Perspective}

In order to understand the impact of methods, it is important to understand their fundamentals. The knowledge to be generated in a research study is to be understood from a particular paradigm, an epistemological world view that provides the researcher with an analytical lens to judge the appropriateness of methods, to make the selection of methods and understand the outcome of methods (Hesse-Biber and Leavy, 2010). To illustrate, if one is coming from a positivistic tradition, researchers are likely to seek evidence in order to discover factual knowledge whereas researchers from a humanist tradition seek to achieve rational accounts of expert judgments (Bardzell, 2013).

This clearly illustrates how epistemological perspectives shape researchers' method choices. Put more concretely for $\mathrm{CCl}$ and user experience research, a more traditional science-trained $\mathrm{CCl}$ researcher would seek empirical evidence of user experience, by measuring users' opinions, feelings, or experiences on aspects such as enjoyment, fun or, arousal and use 'objective' instruments like questionnaires with visual analogue scales or psychophysiological measurements. This could lead researchers to neglect the quality and meaning of children's experiences and lives. Contrarily, the humanistic researcher would engage in a lengthy encounter with the artifact, not to find the 'objective reality' but to interpret the potentialities and meanings of experiences and judge what is most worthy instead (Bardzell, 2013).

Overall, the scientific epistemological perspective seems to dominate in $\mathrm{HCl}$ and $\mathrm{CCl}$ user experience research. This can be evidenced by the numerous research studies that operationalize user experience based on the International Organization for Standardization (ISO)'s definition of user experience (ISO, 2010), which clearly suggests that the desired information is somewhere to be discovered in the user group. Similarly, in HCl's sub community of $\mathrm{CCl}$, the majority of user experience evaluation studies are empirical rather then purely reflective. Many evaluation methods have emerged over the years to capture user experiences with children including evaluation methods that rely on survey techniques (Barendregt et al., 2008, Read et al., 2002), observational techniques (Sim et al., 2005) and verbalization data (Zaman and Abeele, 2010).

Complementing the quantitative methods that had arisen from (post) positivism, qualitative methods have also emerged in $\mathrm{CCl}$, stooled in constructivism and embodiment, like performancebased methods within embodied interaction (Antle et al., 2011). It relies on the premise of interpretative flexibility, i.e. acknowledging that various interpretations of a system may co-exist, inasmuch as it accounts for the embodied nature of our interactions and experiences with technology. It pays more attention to the why-question, complementing the traditional positivist concerns that have mainly been dealing with 'what', 'when', 'how much' questions. From the early years of $\mathrm{CCl}$ research, postmodern thinking has shaped the power relations in research with children in the direction wherein children are generally given a more prominent role in the research process. This is in line with Article 12 of the Convention of the Rights of the Child that emphasizes children's rights to express their views freely 'in all matters affecting the child' (UNICEF, 1989). The interpretivist influence in $\mathrm{CCl}$, both in terms of child empowerment and why-orientedness, is perhaps most clearly manifested in the increasing attention for value-sensitive design as a principled and comprehensive way to account for children's values throughout the participatory design process of new 
technologies (Nouwen et al., 2015). To take ideas forward evaluation plays a central role and the method should ideally match the epistemological perspectives of the design and evaluation process.

\subsection{Construct of User Experience}

In contemporary $\mathrm{HCl}$ and $\mathrm{CCl}$ discourses, the concern to account for user experience in the design, evaluation and implementation of interactive computing systems and in the study of the phenomena surrounding the interaction with technology is still very pertinent. Clearly, contemporary $\mathrm{HCl}$ work has devoted a lot of attention to user experience, and there have been some influential efforts to define its characteristics (Law et al., 2008). In general, ISO's definition has been considered as promising and as a standard for practitioners (Mirnig et al., 2015) even though it still has its limitations (Mirnig et al., 2015, BargasAvila et al., 2011).

It is important to point to the relationship between the operationalisation of the construct of interest and the method choice. When unravelling the definition of user experience, researchers have to specify the extent to which, and how, they deal with and understand building blocks such as user, system, context, user-system interaction effects, and time. There are many frameworks within $\mathrm{HCl}$ that have been synthesized to aid the understanding of this complex interaction within user experience (Schulze and Kromker, 2010, Forlizzi and Battarbee, 2004, Desmet and Hekkert, 2007) yet these frameworks vary in the factors considered important to understanding the interaction and the theoretical grounds.

Some researchers emphasize the importance of accounting for the temporality when investigating notions of user experience (Forlizzi and Battarbee, 2004; Kahneman et al., 1999). These theoretical strands demand methods that distinguish experiences along the time dimension, ranging from anticipated, momentary, episodic, to cumulative, reflective and memorized experiences. Others have focused on the psychological, cognitive and/or emotional processes (Russell, 2003, Desmet and Hekkert, 2007, Norman, 2004) that happen in an experience, hereby typically relying on empirical measurements instruments like psychological measurements or surveys. Traditional $\mathrm{HCl}$ research approached user experience from a narrow perspective, e.g. with characteristics residing in the product to be 'discovered' through expert evaluations or between one user and one product that can be measured in a controlled environment. More recently researchers have started to contribute to a better understanding of user experience as occurring in the interplay between user and product against a particular context. For instance, Hassenzahl's
(2005) model of user experience brings together product features, (intended/apparent) product character, user consequences and the situation in one integrated model. This trend, to account for the broader context in which experiences with technologies unfold, has opened the way for more interpretative methodological approaches. For instance, Forlizzi (2008) supports design culture via a holistic theoretical thinking surrounding the product ecology. Influences from the arts and humanities have further shaped the interpretative readings of interactive artifacts, providing an alternative methodology that does not rely on empirical data gathering but that provides frameworks to think more clearly and talk about the phenomenon of experiences with technology instead. For example, Bardzell and Bardzell's (2008) framework of interaction criticism and McCarthy and Wright's (2004) holistic accounts of the four intertwined threads of experiences are examples of such critical approaches that rely on a notion of experiences as holistic, situated and constructed.

Whilst other researchers take an alternative view, by understanding the operationalization of product qualities and human needs (Schulze and Kromker, 2010). The framework proposed by Desmet and Hekkert (2007) focuses on the user-product interaction and identify three core experiences: emotional experience, aesthetic experience and experience of meaning. It is clear within the field of $\mathrm{HCl}$ that the relationship between the user and the product is a complex paradigm that is interpreted through different lenses.

Within the context of user experience and children, researchers have mainly employed methods to measure momentary experiences and in particular fun, which is generally conceived as a dimension of user experience and one of the major motivators for children to interact with or accept technology (Inkpen, 1997; Malone, 1984). Thus CCI community have developed tools for capturing momentary experience related to fun, examples of tools that have been used to measure fun in $\mathrm{CCl}$ work are the Fun Toolkit (Read and MacFarlane, 2006) and This or That (Zaman, 2009). Nonetheless, it remains important to question whether these methods, even when aimed at measuring the same construct, yield similar results (Zaman et al., 2013, Sim and Horton, 2012), and what the effect is of procedural differences. For instance, even though the Fun Toolkit and This or That have been used to measure fun, the Fun Toolkit explicitly captures expectations prior to interacting with the technology which is not directly captured using the This or That method. Consequently, the potential to reveal different aspects of the user experience construct by employing one or the other method is real, even though both are categorized as user experience 
methods. In some studies, momentary user experience measurement instruments have been repeatedly administered to account for the temporality in children's experiences with technologies (Barendregt et al., 2006). More recently, authors have sought to develop a method that accounts for the temporality by focusing on the coherence in the experience via a retrospective account, and in this way addressing a gap in $\mathrm{CCl}$ research as long term user experience evaluations methods are scarce. This lead to the development of MemoLine (Vissers et al., 2013), inspired by its adult counterpart the UX Curve (Kujala et al., 2011). This tool requires children to complete individual MemoLines for the construct under investigation and this is then used by the researcher as an aid for interviewing the child about their experiences.

\subsection{Role of Child Participant and Adult Researcher}

Several authors have pointed to the varying degrees in which children can participate in research. For instance, Lansdown (2001) has distinguished between involving children in consultative processes, participative initiatives and processes that promote children's advocacy and self-initiation. Hart (1992) has referred to children's varying roles in research with the metaphorical Ladder of Participation. The latter conceptualization has been documented with a number of revisions (Wyness, 2013), and has specified amongst others at the lowest levels processes of manipulation and decoration, to gradually higher levels of children's participation such as tokenism. At the higher level children initiate and direct projects where they may invite adults to share decision making. Wyness (2013) has argued for an alternative conceptualization to Hart's Ladder, classifying children's participation and the involvement of adults horizontally rather than vertically. McLaughlin (2006) has been conceptualizing children's participation on a continuum of consultation, collaboration and user-controlled research. Hill (2006) has presented a more simplified categorization, distinguishing between involving children in consultation versus participation. In IDC research, Druin's (1999) work is probably most citied. She introduced the onion metaphor to describe children's roles in research and practice, tailored to the particularities of interaction design. She links the outside skins of the onion to children's role as an equal research partner, encompassing characteristics of the more interior skins that represent lower degrees of participation and involvement.

Within the context of UX there is a need to understand the extent of the children's involvement, taking into account their attitudes and developmental capabilities. It has been argued that it is not enough to reposition children as subjects of research; they should be engaged as participants in the process (Kellett et al., 2004) and this is important when selecting methods and interacting with children within UX studies. It has been suggested that the methods need to be childfriendly, making the process fun and relevant to the child (Punch, 2002)

Clearly, the role we ascribe to children, whether it comes from a pragmatic or ideological motive, is shaping our method choice. A good example concerns the methods used in participatory design, which have evolved from the concern of giving children a more prominent role in design. In general, the majority of user experience evaluation methods in $\mathrm{CCl}$ rely on active child involvement. Even the engagement in expert evaluations that happen in the absence of children, is typically performed with the child-centred intention to be followed up by a user test later on (Bauuw et al., 2006) or to be enacted from a child persona perspective (Antle, 2008). There is clearly a need for adult input into the evaluation process to engage and help children understand the process. This is evidenced when children have acted as experts evaluators and facilitators of the evaluation process they have been less effective and quickly disengaged with the process (Akobo Wodike et al., 2014). This is ironic as the notion of empowerment that is sought by the $\mathrm{CCl}$ community implies that without aid and encouragement from adults, children cannot fully exercise their agency in research encounters (Gallacher and Gallacher, 2008).

Insights in children's willingness and capability to participate can definitely shape our method choice. For instance, Angel et al. (2014) have reported on the benefits of creative methods for providing a more appropriate language and literacy that matches children' developmental needs. Similarly, Gauntlett (2011) has justified creative methods as an alternative to language-driven qualitative methods. Gauntlett (2007) also argued that creative methods offer children more time to consider their ideas and construct their responses in comparison to traditional methods that request an immediate responses. Relatedly, Niesyto (2000) has advocated visual methods "in order to provide exactly those young people, who have, as experience shows, difficulties with the verbal or written tasks, with adequate possibilities of expression." Hill (2006) has favored innovative methods because these rely more strongly on activities that children are familiar with in school and in recreational settings. Burke (2008) has used photography as a research tool because it "captures perspectives on experience in a format that adults and children can produce with similar levels of technical skill". A critical reflection on children's role in research may reveal new 
challenges, and even result in an ambiguous stance towards children's active participation. For instance, Punch's (2002) approach to account for the particularities of working with children is one of not selecting child-friendly techniques. Punch (2002) rather advises researchers to treat children in the same way as adults, not to patronize them and display their competencies. For example, it has been argued that the typical rephrasing of the oath underestimates children's competences and their credibility as a witness in a court of law (Lyon, 2002). Nevertheless, Punch has also acknowledged that ethical and methodological obstacles remain to overcome in the adult-child research setting. Punch's solution was one of combining traditional and innovative methods, admitting that the creative activities turned out to be an effective way to gain responses from children, and make their participation in research entertaining (Punch, 2002).

\subsection{System}

The system that the user interacts with plays a vital role in influencing the user experience. In PLU-E, which is a framework for planning and conducting evaluations studies with children (McKnight and Read, 2011), the authors make a distinction between different systems those for entertainment, for learning and enabling features of a system. The authors suggest that different methods are required depending on the type of system, for example the This or That method would be used for entertainment (Zaman, 2009). However, for evaluating user experience of a system the PLU-E framework does not address the complex nature of user experience, nor provide a means for analysis of different methods, but is an aid for deciding upon a single method.

When understanding the relationship between a user and a system it is vital that affordances are considered and there are a number of theoretical stands. Gibson (1979) first suggested affordances are the actionable properties between the world and an actor. Within $\mathrm{HCl}$ affordances are (depending upon the theoretical stand) something that exists as a product property or that only exists in the relation to a user and contexts (Norman, 2004). For example, a mobile phone has properties including, a screen and sensors and users may interact with this in a wide variety of ways depending on context. Thus within the PLU-E framework a mobile device may fit into all the three categories but it is the context of use that would influence the choice of evaluation method rather than product properties.

The user experience categorized as an essentialist perspective is a property of the product (causally homogeneous) and thus the objective evaluation can be made. This would enable inspection based methods to be performed on technology for children, with a view that problems with the functionality and properties of a system can be identified and fixed. However, this does not take into consideration what the user does with the system or appropriates the system in ways the designer did not perceive.

In contrast, taking a more contextual perspective system properties are only one aspect in forming the user experience. This causally heterogeneous stance advocates the use of several methods and opens the way for non-empirical methods as well. These non-empirical methods offer insight into why and how children interact with a system, to enhance our understanding of their experiences.

\subsection{Practical and Ethical Concerns}

There are many practical and ethical considerations that need to be considered in method selection. Tools such as CHECk have been developed by the $\mathrm{CCl}$ community to help address ethical concerns (Read et al., 2013) that will directly influence the evaluation. Practical concerns may relate to location, number of children, the duration of the evaluation and use of any equipment. There is an interwoven relationship amongst the dimension. For example, if the technology under investigation was the Oculus Rift and the UX construct was fun this would influence the children's role, as there are minimum age recommendations and practical concerns over the duration, as well as ethical concerns over nausea and motion sickness (Davis et al., 2014).

Children are one of many groups considered vulnerable in regards to research studies. This is mainly due to their physical size, strength, developing cognitive experience, and lack of knowledge and experience rendering them dependent on the adults around them (Morrow and Richards, 1996). The British Educational research Association (BERA) provide guidance for researchers covering areas such as legal compliance, and recognizing distress or discomfort in children to ensure children are kept from emotional or other harm (BERA, 2011). Privacy is also an important aspect of children's vulnerability. There may be situations where it could be dangerous for a child to be identifiable in a piece of research, an extreme being a child in witness protection, and researchers need to be aware of the importance of following data protection procedures and keeping data anonymous.

Selecting an evaluation method is still down to judgment of the researcher based on their interpretation of the method, their epistemological perspective and the construct under investigation. A framework similar to those offered in the $\mathrm{HCl}$ domain addressing the needs of the design community but addressing evaluation methods may 
help new researchers and practitioners in $\mathrm{CCl}$ critically assess the suitability of a particular method for use with children.

\section{METHOD IMPACT ASSESSMENT FRAMEWORK}

Based upon the literature, a theoretical method impact assessment framework has been synthesized and is presented in figure 1 .

The researchers, children and the system that is to be evaluated is encapsulated within the practical and ethical concerns associated with evaluation studies with children. The researchers bring their epistemological perspective to the evaluation study and their beliefs will influence the role of the child within the study. The epistemological perspective of the researcher may impact on method selection.

The child will interact with the system that will provide feedback. This representation is for interaction with a single device and does not depict multi-user interaction. The type of system being evaluated will influence the user experience constructs under investigation. These relationships between researchers, children and the system should not be neglected when assessing the suitability of an evaluation method. They will ultimately influence the choice and suitability of a given method and how and what data can be reported by the children.

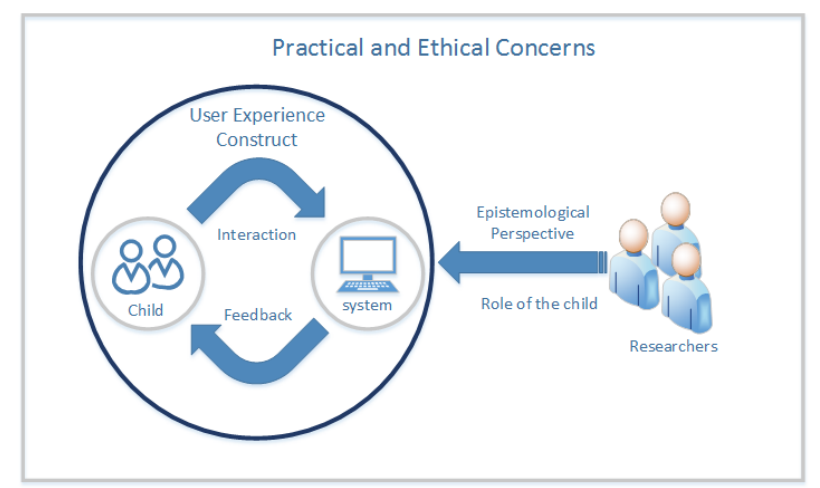

Figure 1: Method Impact Assessment Framework (MIA)

\section{DISCUSSION AND CONCLUSION}

The framework was synthesized based on a theoretical foundation drawn from the literature. The aim of the framework is to encourage a critical reflection of the suitability of a user experience evaluation method, for a given context and to enable a greater understanding of the differences between methods to be formed. There are different lenses that can be applied within the context of user experience and frameworks have been synthesized based upon these (Forlizzi, 2008), however they are not specifically dealing with children.
Theoretically synthesized, the framework offers five dimensions: (1) the role of the child, (2) the user experience construct, (3) system, (4) epistemological perspective, (5) Practical and Ethical Concerns. Although other dimensions could have been construed, these were judged to be the most pertinent to understanding evaluation methods with children. Researchers who are strongly morally driven may be so concerned to improve the role of the child in the process of data gathering, that they forget, that many children are likely to be outcome oriented and thus easily disappointed or disillusioned when there is no clear outcome of their involvement (Hill, 2006). The CHECk tool (Read et al., 2013) encourages researchers to share findings with the participants and it may well be, that for ethical reasons, the results should not be broken down to an individual level to avoid disappointment or disillusioning the child. The MIA framework encourages researchers to think about the impact the method has on the child and their role within the study. Currently within $\mathrm{CCl}$ their lacks any systematic research on children's experiences with the research process, their only appears to be anecdotal feedback.

The epistemological motives should be made explicit in order to know how to stipulate the measures of success of the method. To illustrate, from a social constructionism perspective, children's narratives are approached as a way to create an understanding with children, whereas from a positivistic standpoint, it may be perceived as a way to reveal the underlying objective truth. Alternatively, from a more action research perspective, the use of narratives may be considered as a means of giving children a voice and a meaningful active role in the research. This researcher's perspective will inform other dimensions and influence method selection.

If evaluation focuses on more than one system for example evaluating two different games, system differences may impact user experience and it may be vital to capture this information. Through understanding the system affordances, one can describe the system in terms of the functional possibilities that extend to a particular individual and thus improve the design. Capturing and aiding the capabilities of children is important as adults have been shown to over and underestimate children's capabilities (Cordovil and Barreiros, 2010).

Currently method selection is rooted in conjectured assumptions of the suitability of a method within a given context, the experience of the researchers or based on literature, the framework will provide a critical lens to support the decision making process. Further research is required to map existing $\mathrm{CCl}$ methods to this framework to aid method selection. 


\section{REFERENCES}

Akobo Wodike, O., Sim, G. \& Horton, M. 2014. Empowering Teenagers to Perform a Heuristic Evaluation of a Game. 28th British $\mathrm{HCl}$ Conference. Southport, UK.: BCS.

Angell, C., Alexander, J. \& Hunt, J. A. 2014. 'Draw, write and tell': A literature review and methodological development on the 'draw and write'research method. Journal of Early Childhood Research, 1476718X14538592.

Antle, A. N. 2008. Child-based personas: need, ability and experience. Cognition, Technology \& Work, 10, 155-166.

Antle, A. N., Corness, G. \& Bevans, A. 2011. Springboard: Designing image schema based embodied interaction for an abstract domain. Whole Body Interaction. Springer.

Bardzell, J. 2013. Critical and Cultural Approaches to $\mathrm{HCl}$. The SAGE Handbook of Digital Technology Research, 130.

Bardzell, J. \& Bardzell, S. Interaction criticism: a proposal and framework for a new discipline of hci. CHI'08 Extended Abstracts on Human Factors in Computing Systems, 2008. ACM, 2463-2472.

Barendregt, W., Bekker, M. \& Baauw, E. 2008. Development and evaluation of the problem identification picture cards method. Cognition, Technology and Work, 10, 95-105.

Barendregt, W., Bekker, M., Bouwhuis, D. G. \& Baauw, E. 2006. Identifying usability and fun problems in a computer game during first use and some practice:. International Journal Human Computer Interaction, 64, 830-846.

Bargas-Avila, J. A., \& Hornbaek, K. 2011. Old wine in new bottles or novel challenges: a critical analysis of empirical studies of user experience. Proceedings of the SIGCHI Conference on Human Factors in Computing Systems. Vancouver, BC, Canada: ACM.

Bauuw, E., Bekker, M. M. \& Markopoulos, P. 2006. Assessing the applicability of the structured expert evaluation method (SEEM) for a wider age group. Interaction Design and Children. Tampere: ACM.

Bell, A. 2007. Designing and testing questionnaires for children. Journal of Research in Nursing, 12, 461-469.

Bera. 2011. Ethical Guidelines for Educational Research. [Accessed 22/07/15].

Burke, C. 2008. Play in focus.
Cordovil, R. \& Barreiros, J. 2010. Adults' perception of children's height and reaching capability. Acta psychologica, 135, 24-29.

Davis, S., Nesbitt, K. \& Nalivaiko, E. A Systematic Review of Cybersickness. Proceedings of the 2014 Conference on Interactive Entertainment, 2014. ACM, 1-9.

Desmet, P. \& Hekkert, P. 2007. Framework of Product Experience. International Journal of Design, 1, 57-66.

Druin, A. 1999. The design of children's technology, Morgan Kaufmann Publishers San Francisco.

Forlizzi, J. 2008. The product ecology: Understanding social product use and supporting design culture. . International Journal of design, 2, 11-20.

Forlizzi, J. \& Battarbee, K. 2004. Understanding experience in interactive systems. Proceedings of the 5th conference on Designing interactive systems: processes, practices, methods, and techniques. Cambridge, MA, USA: ACM.

Gallacher, L.-A. \& Gallacher, M. 2008. Methodological Immaturity in Childhood Research? Thinking through 'participatory methods'. Childhood, 15, 499-516.

Gauntlett, D. 2007. Creative explorations: New approaches to identities and audiences, Routledge.

Gauntlett, D. 2011. Creative Explorations: New Approaches to Identities and Audiences., London, Routledge.

Gibson, J. J. 1979. The Ecological Approach to visual Perception, Boston, Houghton Miffflin.

Hanna, L., Risden, K. \& Alexander, K. J. 1997. Guidelines for usability testing with children. Interactions, 4, 9-14.

Hart, R. A. 1992. Children's participation: From tokenism to citizenship. UNICEF Innocenti Research Centre.

Hartson, H. R., Andre, T. S. \& Williges, R. C. 2003. Criteria for Evaluating Usability Evaluation Methods. International Journal Human Computer Interaction, 15, 145-181.

Hassenzahl, M. 2005. The thing and I: understanding the relationship between user and product. Funology. Springer.

Hassenzahl, M., Diefenbach, S. \& Goritz, A. 2010. Needs, affects, and interactive products - facets of user experience. Interacting with Computers, 22, 353-362.

Hesse-Biber, S. N. \& Leavy, P. 2010. Handbook of Emergent Methods, New York, Guilford Press. 
Hill, M. 2006. Children's Voices on Ways of Having a Voice Children's and young people's perspectives on methods used in reserach and consultation. Childhood, 13, 69-89.

Inkpen, K. 1997. Three Important Research Agendas for Educational Multimedia: Learning, Children and Gender. Educationl MultiMedia 97. Calgary.

Iso 2010. Ergonomics of human system interaction - Prt 210: Human-centred design for interactive system. Switserland: International Standards Organisation.

Kahneman, D., Diener, E. \& Schwarz, N. 1999. Well-being: Foundations of hedonic psychology, Russell Sage Foundation.

Kellett, M., Forrest, R., Dent, N. \& Ward, S. 2004. "Just Teach us the Skills Please, We'll Do the Rest": Empowering Ten-Year-Olds as Researchers. Children and Society, 18, 329-343.

Kujala, S., Roto, V., Väänänen-Vainio-Mattila, K., Karapanos, E. \& Sinnelä, A. 2011. UX Curve: A method for evaluating long-term user experience. Interacting with Computers, 23, 473483.

Lansdown, G. 2001. Promoting children's participation in democratic decision-making. UNICEF Innocenti Research Centre.

Law, E. L.-C., Roto, V., Hassenzahl, M., Vermeeren, A. P. O. S. \& Kort, J. 2009. Understanding, scoping and defining user experience: a survey approach. Proceedings of the SIGCHI Conference on Human Factors in Computing Systems. Boston, MA, USA: ACM.

Law, E. L.-C., Roto, V., Vermeeren, A. P. O. S., Kort, J. \& Hassenzahl, M. 2008. Towards a Shared Definition of User Experience. CHI 2008. Florence: ACM Press.

Lyon, T. 2002. Child witnesses and the oath. In: WESTCOTT, H. L., DAVIES, G. M. \& BULL, R. H. C. (eds.) Children's testimony: $A$ handbook of psychological research and forensic practice. Chichester: Wiley.

Malone, T. W. (ed.) 1984. Heuristics for designing enjoyable user interfaces : Lessons from computer games, Norwood, N .J: Ablex.

Markopoulos, P. \& Bekker, M. 2003. On assessment of usability testing methods for children. Interacting with Computers, 15, 227243.

Mcknight, L. \& Read, J. C. 2011. PLU-E: a proposed framework for planning and conducting evaluation studies with children. Proceedings of the 25th BCS Conference on Human-Computer Interaction. Newcastle-upon-Tyne, United Kingdom: British Computer Society.
Mclaughlin, H. 2006. Involving Young Service Usres as Co-Reserachers: Possibilities, Benefits and Costs. British Journal of Social Work, 36, 1395-1410.

Mirnig, A. G., Meschtscherjakov, A., Wurhofer, D., Meneweger, T. \& Tscheligi, M. 2015. A Formal Analysis of the ISO 9241-210 Definition of User Experience. Proceedings of the 33rd Annual ACM Conference Extended Abstracts on Human Factors in Computing Systems. Seoul, Republic of Korea: ACM.

Morrow, V. \& Richards, M. 1996. The ethics of social research with children: An overview. Children \& Society, 10, 90-105.

Niesyto, H. 2000. Youth research on video selfproductions reflections on a social- aesthetic approach. Visual Studies, 15, 135-153.

Norman, D. A. 2004. Emotional design: Why we love (or hate) everyday things, Basic books.

Nouwen, M., Mechelen, M. V. \& Zaman, B. 2015. A value sensitive design approach to parental software for young children. Proceedings of the 14th International Conference on Interaction Design and Children. Boston, Massachusetts: ACM.

Pucillo, F. \& Cascini, G. 2014. A framework for user experience, needs and affordances. Design Studies, 35, 160-179.

Punch, S. 2002. RESEARCH WITH CHILDREN The same or different from research with adults? Childhood, 9, 321-341.

Read, J. C. 2012. Evaluating artefacts with children: age and technology effects in the reporting of expected and experienced fun. 14th ACM International Conference on Multimodal Interaction. Santa Monica: ACM.

Read, J. C., Horton, M., Sim, G., Gregory, P., Fitton, D. \& Cassidy, B. 2013. CHECk: a tool to inform and encourage ethical practice in participatory design with children. $\mathrm{CHI}$ '13 Extended Abstracts on Human Factors in Computing Systems. Paris, France: ACM.

Read, J. C. \& Macfarlane, S. 2006. Using the Fun Toolkit and Other Survey Methods to Gather Opinions in Child Computer Interaction. Interaction Design and Children. Tampere: ACM Press.

Read, J. C., Macfarlane, S. J. \& Casey, C. Endurability, Engagement and Expectations: Measuring Children's Fun. Interaction Design and Children, 2002 Eindhoven, The Netherlands. Shaker Publishing, 189 - 198.

Russell, J. A. 2003. Core Affect and the Psychological Construction of Emotion. Psychological Review, 110, 145-172. 
Schulze, K. \& Kromker, H. 2010. A framework to measure user experience of interactive online products. Proceedings of the 7th International Conference on Methods and Techniques in Behavioral Research. Eindhoven, The Netherlands: ACM.

Sim, G. \& Horton, M. 2012. Investigating children's opinions of games: Fun Toolkit vs This or That. Interaction Design and Children. Bremen, Germany.: ACM.

Sim, G., Macfarlane, S. \& Horton, M. 2005. Evaluating usability, fun and learning in educational software for children. World Conference on Educational Multimedia, Hypermedia and Telecommunications. Montreal: AACE.

Unicef. 1989. UN Convention on the Rights of the child [Online]. Available: http://www.unicef.org/crc/ [Accessed 02/07/15 2015].

Vissers, J., Bot, L. D. \& Zaman, B. 2013. MemoLine: evaluating long-term UX with children. Proceedings of the 12th International Conference on Interaction Design and Children. New York, New York: ACM.
Westcott, H. L. \& Littleton, K. S. 2005. Exploring Meaning in Interviews with Children. In: GREENE, S. \& HOGAN, D. (eds.) Reseraching Children's Experience. London: Sage.

Wright, P. \& Mccarthy, J. 2004. Technology as experience, MIT Press.

Wyness, M. 2013. Children's participation and intergenerational dialogue: Bringing adults back into the analysis. Childhood, 20, 429-442.

Zaman, B. Introduction and validation of a pairwise comparison scale for UX evaluations and benchmarking with preschoolers. Interact, 2009 Uppsala. Springer, 634-637.

Zaman, B. \& Abeele, V. V. 2010. Laddering with Young Children in User Experence Evaluations: Theoretical Groundings and a Practical Case. IDC. Barcelona: ACM.

Zaman, B., Abeele, V. V. \& De Grooff, D. 2013. Measuring product liking in preschool children: An evaluation of the Smileyometer and This or That methods. International Journal of ChildComputer interaction, 1, 61-70. 